\title{
Mild dyserythropoiesis and $\beta$-like globin gene expression imbalance due to the loss of histone chaperone ASF1B
}

Petros Papadopoulos ${ }^{1,2^{*}}$ D, Athanassia Kafasi ${ }^{3}$, Iris M. De Cuyper ${ }^{3}$, Vilma Barroca ${ }^{4,5}$, Daniel Lewandowski ${ }^{4,5}$, Zahra Kadri ${ }^{6}$, Martijn Veldthuis ${ }^{7}$, Jeffrey Berghuis ${ }^{7}$, Nynke Gillemans ${ }^{1}$, Celina María Benavente Cuesta ${ }^{2}$, Frank G. Grosveld ${ }^{1}$, Rob van Zwieten ${ }^{3,7}$, Sjaak Philipsen ${ }^{1}$, Muriel Vernet ${ }^{4 \dagger}$, Laura Gutiérrez ${ }^{1,2,8,}$ and George P. Patrinos ${ }^{9,10 \dagger}$

\begin{abstract}
The expression of the human $\beta$-like globin genes follows a well-orchestrated developmental pattern, undergoing two essential switches, the first one during the first weeks of gestation $(\varepsilon$ to $\gamma)$, and the second one during the perinatal period ( $\gamma$ to $\beta$ ). The $\gamma$ - to $\beta$-globin gene switching mechanism includes suppression of fetal ( $\gamma$-globin, $\mathrm{HbF}$ ) and activation of adult ( $\beta$-globin, $\mathrm{HbA}$ ) globin gene transcription. In hereditary persistence of fetal hemoglobin $(\mathrm{HPFH})$, the $\gamma$-globin suppression mechanism is impaired leaving these individuals with unusual elevated levels of fetal hemoglobin ( $\mathrm{HbF}$ ) in adulthood. Recently, the transcription factors KLF1 and BCL11A have been established as master regulators of the $\gamma$ - to $\beta$-globin switch. Previously, a genomic variant in the KLF1 gene, identified by linkage analysis performed on twenty-seven members of a Maltese family, was found to be associated with HPFH. However, variation in the levels of $\mathrm{HbF}$ among family members, and those from other reported families carrying genetic variants in $K L F 1$, suggests additional contributors to globin switching. ASF1B was downregulated in the family members with HPFH. Here, we investigate the role of ASF1B in $\gamma$ - to $\beta$-globin switching and erythropoiesis in vivo. Mouse-human interspecies ASF1B protein identity is $91.6 \%$. By means of knockdown functional assays in human primary erythroid cultures and analysis of the erythroid lineage in Asflb knockout mice, we provide evidence that ASF1B is a novel contributor to steady-state erythroid differentiation, and while its loss affects the balance of globin expression, it has no major role in hemoglobin switching.
\end{abstract}

Keywords: Dyserythropoiesis, Hemoglobin switching, Hereditary persistence of fetal hemoglobin (HPFH), Thalassemia, Gene expression, Erythropoiesis, ASF1B, KLF1, BCL11A

\section{Background}

The expression of the $\beta$-like globin genes follows a wellorchestrated developmental pattern, undergoing two essential switches, the first one during the first weeks of gestation $(\varepsilon$ to $\gamma)$, and the second one around birth $(\gamma$ to $\beta)$

\footnotetext{
* Correspondence: petros.papadopoulos@salud.madrid.org

${ }^{\dagger}$ Muriel Vernet, Laura Gutiérrez and George P. Patrinos contributed equally to this work. 'Department of Cell Biology, Erasmus MC, Rotterdam, The Netherlands

${ }^{2}$ Department of Hematology, Hospital Clínico San Carlos, Instituto de Investigación Sanitaria San Carlos (IdISSC), Madrid, Spain

Full list of author information is available at the end of the article
}

[1-4]. Therefore, fetal hemoglobin (HbF), composed of two $\alpha$-globin and two $\gamma$-globin chains, is the dominant type of hemoglobin during the fetal stages of development. Around birth, $\mathrm{HbF}$ is gradually replaced by adult hemoglobin $(\mathrm{HbA})$, consisting of two $\alpha$-globin and two $\beta$ globin chains. Already at 6 months of age, the major hemoglobin in the circulation is HbA [5]. However, residual amounts of $\mathrm{HbF}$ continue to be synthesized throughout adult life, and the amounts vary considerably, with the large majority of adults having less than $1 \%$ of HbF. Our understanding of $\beta$-like globin transcriptional 
control is historically based on Mendelian models of inheritance of natural mutants. Indeed, a series of genetic variants of the $\beta$-globin cluster have been discovered that impair the fetal-to-adult hemoglobin switch, leading to persistent $\gamma$-globin expression and elevated $\mathrm{HbF}$ throughout adult life. This condition is termed hereditary persistence of fetal hemoglobin (HPFH) [6]. There are two types of $\mathrm{HPFH}$ variants in the $\beta$-globin locus: point mutations in the promoter of the $\gamma$-globin genes (HBG1 or $H B G 2$ ) and deletions removing substantial regions of the $\beta$-globin cluster, often including the $\beta$-globin gene $(H B B)$ [7]. A range of conditions characterized by $\mathrm{HbF}$ levels that do not fit clear Mendelian inheritance models or the typical HPFH phenotype, i.e., high $\mathrm{HbF}$ levels accompanied by concomitant lower $\mathrm{HbA}_{2}\left(\alpha_{2} \delta_{2}\right)$ levels, have been previously reported. Although some of this variability can be explained by the $\beta$-globin cluster haplotype, a substantial proportion of the $\mathrm{HbF}$ increase is not linked to the $\beta$ globin cluster, suggesting multi-factorial genetic players in the fine-tuning of $\beta$-like globin gene expression regulation.

It is now evident that common $\mathrm{HbF}$ variation is a quantitative genetic trait, shaped by common polymorphisms in genes that are not related to the human $\beta$-like globin gene cluster. There are only a few examples of such SNPs in genes, affecting for example BCL11A (MIM 606557) residing on chromosome 2 [8-11] and the intergenic region between the MYB (MIM 189990) [12] and HBS1L (MIM 612450) genes that resides on chromosome 6q22.3 $[7,13-15]$. These genes have been identified by genomewide association or traditional linkage analysis approaches. In addition, it has been previously reported that genetic variants in the KLF1 (MIM 600599) gene are causative for $\mathrm{HPFH}$, in part by rendering the expression of $B C L 11 A$ low [16-18]. The identification of some of the direct transcriptional regulatory regions within the $\beta$-like globin gene cluster targeted by these transcription factors has been reported [15, 19-21].

The extremely high variation of $\mathrm{HbF}$ levels observed in carriers of the KLF1 p.K288X variant led us to further examine other potential contributors to the fine-tuning of the $\gamma$ - to $\beta$-globin gene expression balance [22].

Whole transcriptome analysis performed on mRNA from primary erythroid cultures revealed that expression levels of $A S F 1 B$ (MIM 609190), located in chromosome 19 , close to the region that showed the highest LOD scores when using multi-point parametric analysis at a penetrance of $90 \%$ [16], were downregulated to $70 \%$ in $\mathrm{HPFH}$ family members. ASF1B, anti-silencing function $1 \mathrm{~B}$ histone chaperone gene, is a member of the evolutionary conserved family of $\mathrm{H} 3 / \mathrm{H} 4$ histone chaperone proteins. In humans and mice, there are two paralogues of the Asf1 protein in yeast, namely ASF1A (MIM 609189) and ASF1B [23-26]. Both ASF1A and ASF1B participate in DNA synthesis-independent assembly of histone H3.3 into chromatin [27]. However, ASF1A and $A S F 1 B$ are distinct in expression pattern and function. While $A S F 1 A$ is ubiquitously expressed, $A S F 1 B$ is expressed in highly proliferating tissues, and its expression levels decrease in terminally differentiated and quiescent cells [28]. It was described previously that ASF1B and the histone $\mathrm{H} 3.3$ promote pancreatic $\beta$-cell proliferation in a synergistic manner [29]. The ASF1B protein is the substrate of the tousled-like kinase family of cell cycle-regulated kinases [30-32] and is thought to play a key role in modulating the nucleosome structure of chromatin by ensuring a constant supply of histones at sites of nucleosome assembly [27], while interacting directly with transcription regulators [23, 24, 33, 34]. ASF1B also cooperates with chromatin assembly factor 1 (CAF-1) to promote replication-dependent chromatin assembly [35, 36], but it does not participate in replication-independent nucleosome deposition mediated by ASF1A and HIRA [28, 37]. Mouse-human interspecies ASF1B protein identity is $91.6 \%$.

In the present study, we have employed lentivirusmediated knockdown in primary human erythroblast cultures and analyzed the Asf $1 b \mathrm{KO}$ mice [38] to demonstrate that ASF1B histone chaperone is functionally linked to steady-state erythropoiesis. Our data shows that loss of ASF1B compromises steady-state erythropoiesis with modest effects on the regulation of the $\beta$-like globin genes.

\section{Results}

ASF1B is downregulated in human primary erythroid progenitors carrying the $\mathrm{p} . \mathrm{K} 288 \mathrm{X}$ KLF1 variant

A SNP in the KLF1 gene resulting in p.K288X protein variant, causative of the inherited HPFH in 10 out of 27 recruited members of a Maltese family, was reported previously [16]. The identification of the point mutation in the Maltese family was achieved through SNP linkage analysis, which pointed to a region in chromosome 19p13.12-13 that showed the highest LOD scores when using multi-point parametric analysis at a penetrance of $90 \%$ [16]. No evidence of linkage was observed to other regions, including the $H B B$ locus and the $\mathrm{HPFH}$-linked loci of chromosomes $2 \mathrm{q} 33$ and 6q22.3. However, $\mathrm{HbF}$ levels ranged from $\sim 3 \%$ to almost $20 \%$, suggesting other contributing factors to the variation of HbF levels among HPFH family members [16].

Examining in more detail the region in chromosome 19 that showed the highest LOD scores and the expression in erythroid primary cultures of the neighboring genes in close proximity (GSE22109), we identified $A S F 1 B$, which was found to be downregulated in HPFH family members (Fig. 1a) [16]. As shown in Fig. 1a, and as previously reported, KLF1 targets $B C L 11 A, C D 44$ 

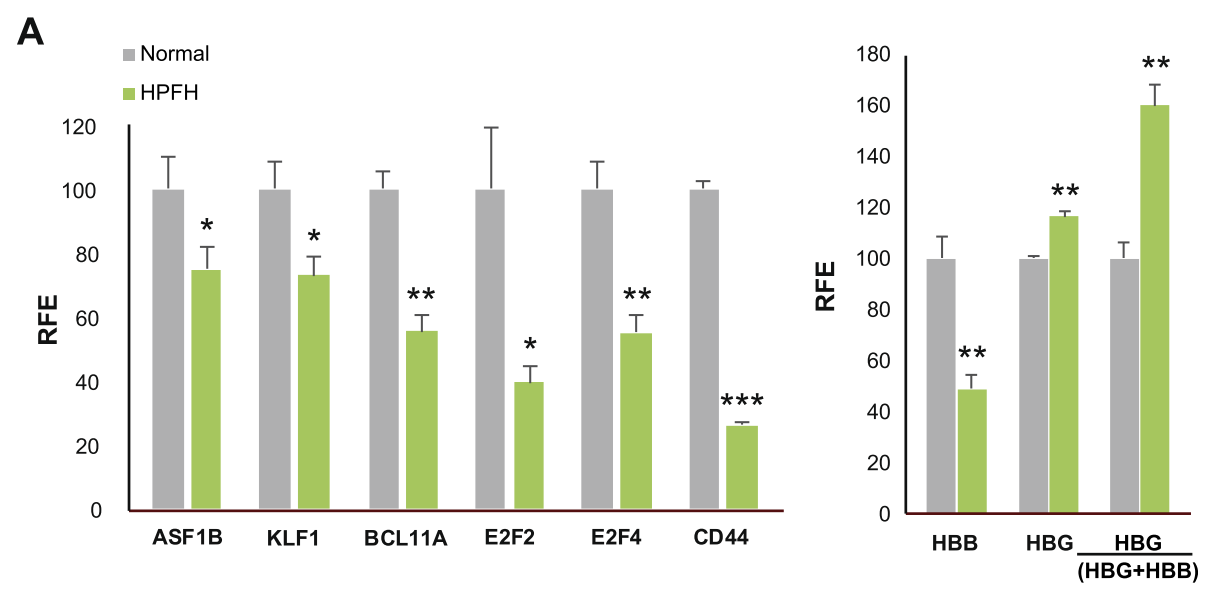

B
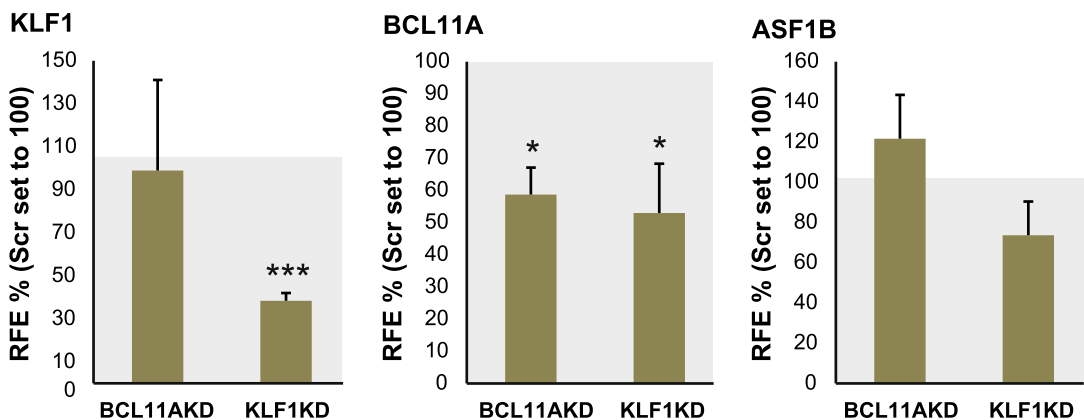

Fig. 1 ASF1B is downregulated in the primary erythroid progenitors carrying the p.K288X KLF1 variant. a Expression analysis from publicly available microarray data (GSE22109) [16] derived from cultured primary erythroid cells (HEPs) of Maltese family members with HPFH (green bars, $n=3$ ) and normal family members (gray bars, $n=3$ ). Family members with HPFH display reduction of BCL11A, ASF1B, E2F2, E2F4, CD44, and HBB and increased $\mathrm{HBG} /(\mathrm{HBB}+\mathrm{HBG})$ ratio. Mean and standard deviation are depicted. $T$ test $p$ values are indicated. ${ }^{*} p<0.05 ;{ }^{* *} p<0.005 ;{ }^{* * *} p<$ 0.0005. b Analysis of KLF1, BCL11A, and ASF1B expression by RT-qPCR on HEPs derived from buffy coats from healthy individuals and transduced with shRNA lentiviruses targeting KLF1 and BCL11A. Knockdown of either factor does not influence significantly the ASF1B expression. Expression levels are normalized setting expression levels of mock knockdown controls at 100. Mean and standard deviation are depicted. Shadowed box at 100 corresponds to the expression levels in mock knockdown controls. $T$ test $p$ values are indicated. ${ }^{*} p<0.05 ;{ }^{* *} p<0.005 ;{ }^{* * *} p<0.0005$

(MIM 107269), E2F2 (MIM 600426), E2F4 (MIM 600659), and $H B B$ (MIM 141900), were significantly downregulated, and the $\gamma$-globin versus total $\gamma+\beta$-globin expression ratio was increased in primary erythroid cells derived from HPFH individuals [16]. We confirmed that $A S F 1 B$ mRNA levels were significantly reduced to $70 \%$ in $\mathrm{HPFH}$ family members presenting with the highest $\mathrm{HbF}$ levels. Since we could not exclude that the transcription of $A S F 1 B$ is dependent on KLF1 or BCL11A activities, we performed knockdown of either KLF1 or BCL11A in healthy human primary erythroid progenitors and analyzed the $A S F 1 B$ expression levels accordingly. $B C L 11 A$ downregulation did not affect the expression of $A S F 1 B$ at all, while KLF1 knockdown resulted in a small reduction of $A S F 1 B$ expression which did not reach statistical significance (Fig. 1b). This suggests that the significant reduction of $A S F 1 B$ expression levels in primary erythroid cells cultured from the HPFH family members might be partially, but not exclusively, due to transcription regulation by KLF1.

\section{Knockdown of ASF1B in human primary erythroid cells} induces $\gamma$-globin expression

To functionally assess the consequences of $A S F 1 B$ downregulation on human $\beta$-globin gene expression, we performed knockdown experiments on primary human erythroblasts derived from healthy donors. We used three shRNA lentiviral constructs against $A S F 1 B$, of which two (\#23 and \#24, Supplementary Table 1) resulted in efficient knockdown as measured by RT-qPCR. Therefore, we used those two for further analysis. We included BCL11A and KLF1 lentiviral shRNA-transduced cells as the positive controls for $\gamma$-globin reactivation and a non-specific scrambled (Scr) shRNA as the negative control. After lentiviral transduction and $24 \mathrm{~h}$ selection with puromycin, cells were induced to differentiate (+Epo and holotransferrin), and after $24 \mathrm{~h}$, cells were collected for analysis. We confirmed the shRNA-mediated downregulation of $B C L 11 A, K L F 1$, and $A S F 1 B$ transcripts by RT-qPCR (Fig. 2a). We then investigated the impact of $A S F 1 B$ knockdown on BCL11A and KLF1 expression. We found 


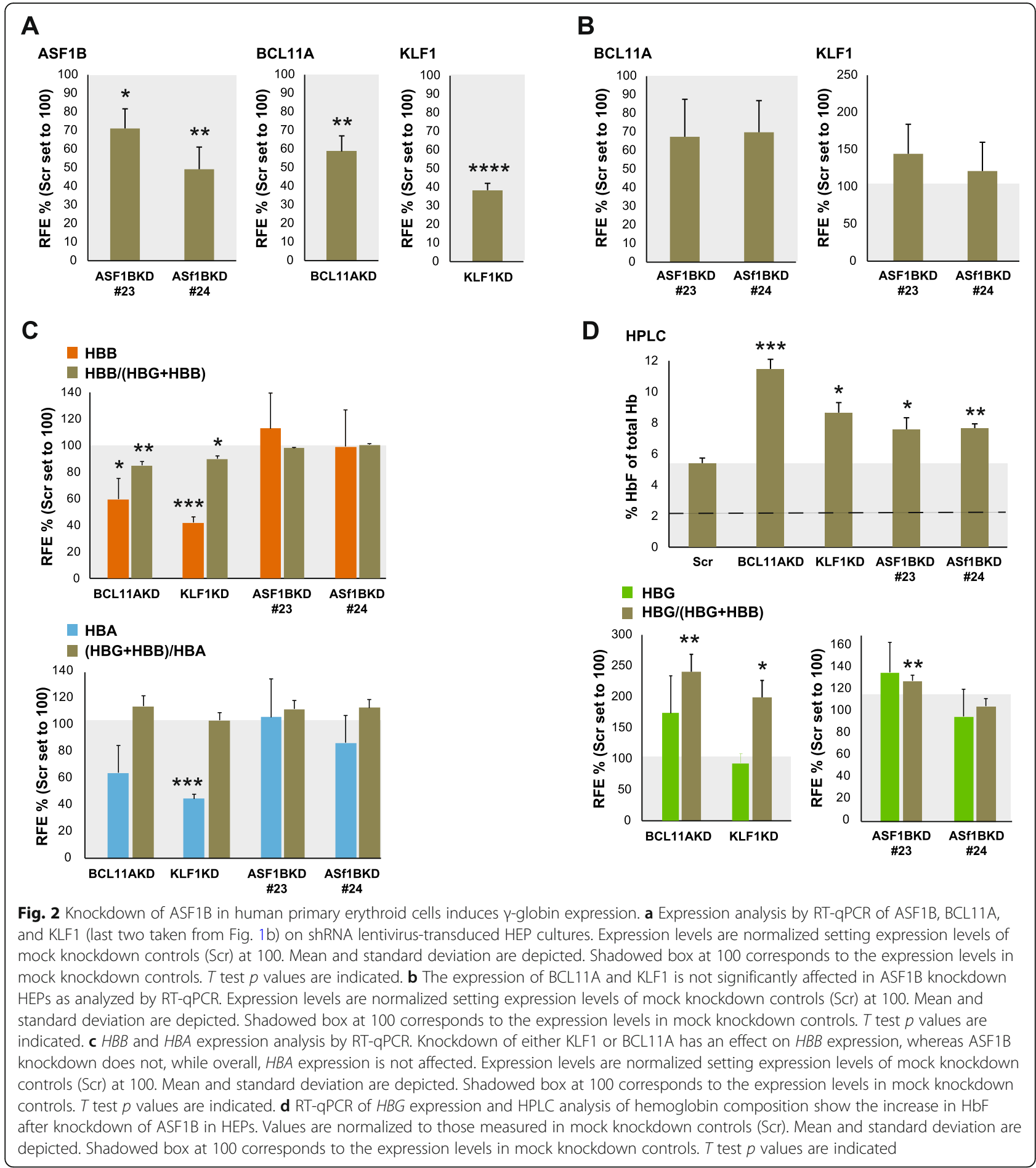

that knockdown of $A S F 1 B$ did not affect the expression of KLF1 and BCL11A levels significantly (Fig. 2b). It is known that one of the principal targets of KLF1 is the $H B B$ gene (encoding $\beta$-globin) $[39,40]$, and we could verify that by knocking down the $K L F 1$ gene expression (Fig. 2c). Indirect downregulation of $H B B$ gene transcription, due to the upregulation of $\gamma$-globin expression, has been reported upon BCL11A knockdown in human proerythroblasts [41]. We also observed this in our human erythroid cultures (Fig. 2d). In contrast, $A S F 1 B$ knockdown did not reduce the levels of $H B B$ mRNA expression (Fig. 2c). $H B A$ expression levels were also not altered significantly in the ASF1B KD experiments (Fig. 2c). When measuring hemoglobin composition from the lentiviral-transduced 
HEPs by qRT-PCR and HPLC, we observed that ASF1B knockdown increased $\gamma$-globin expression, as shown by the percentage of $\mathrm{HbF}$ of total hemoglobin in the samples (Fig. 2d).

\section{Asf1b KO mice display mild dyserythropoiesis}

To investigate the potential contribution of ASF1B in erythropoiesis and globin gene expression regulation, we set out to study these processes in Asf1b knockout (KO) mice. Complete blood count was performed on blood samples from adult $A s f 1 b \mathrm{KO}$ mice and wild-type (WT) littermates (Fig. 3a). Interestingly, Asf1b KO mice present with a reduced red blood cell (RBC) count $(8.62$ versus $9.34 \times 10^{9}$ cells $\left./ \mathrm{ml} ; p<0.05\right)$, an increased mean cell volume (MCV 49.15 versus $46.10 \mathrm{fL} ; p<10^{7}$ ), and an increased mean corpuscular hemoglobin ( $\mathrm{MCH} 15.62$ versus 14.80; $p>10^{-6}$ ), suggestive of compensatory anemia. Their spleen was significantly enlarged (116.91 versus $90.20 \mathrm{mg} ; p<0.05$ ), supporting this notion, considering the increased tendency of the body size of $A s f 1 b \mathrm{KO}$ mice that did not reach statistical significance (Table 1).

We next set out to study the erythroid compartment in the bone marrow and spleen of Asflb $\mathrm{KO}$ mice (Fig. $3 \mathrm{~b}, \mathrm{c})$. The bone marrow presented an accumulation of early erythroid progenitors $\left(\mathrm{CD} 71^{+} \mathrm{Ter} 119^{\text {neg }}\right)$ and a significant reduction of the Ter119 positive cells, "A" $\left(\mathrm{CD} 71^{+} \mathrm{FSC}^{\text {high }}\right)$, "B" $\left(\mathrm{CD} 71^{+} \mathrm{FSC} \mathrm{low}^{\text {low }}\right)$, and "C" $\left(\mathrm{CD} 71^{\text {neg }} \mathrm{F}-\right.$ $\mathrm{SC}^{\text {low }}$ ) corresponding to more mature erythroid cells (Fig. 3b, bar graph), based on the gating strategy by Socolovsky [42]. When the megakaryocyte-erythroidprogenitor (MEP) fraction was analyzed, we observed an increase of these progenitors in Asf1b KO bone marrow (Fig. 3b, dot plot). Analysis of the splenic erythroid compartment revealed a significant increase of early erythroid progenitors (proerythroblasts; CD71 ${ }^{+}$Ter119${ }^{n e g}$ ), accompanied by a significant reduction of the more mature cells, specially the population " $\mathrm{C}$," indicative of moderate stress erythropoiesis (Fig. 3c). Altogether, these data suggest that Asf1b KO mice present with mild dyserythropoiesis and have engaged stress erythropoiesis in the spleen.

\section{Persistence of embryonic globin expression in adult Asf1b KO mice}

We next set out to analyze the expression of the $\beta$-like globin genes in the blood, bone marrow, and spleen of Asf1b KO mice and WT littermates. In mice, the developmental pattern of $\beta$-like globin gene expression is marked by the expression of $\varepsilon y$ and $\beta$ h1 in the embryonic stage, which is replaced by $\beta$ maj $+\beta$ min at the fetal stage. RT-qPCR revealed significant upregulation of the expression of $\varepsilon y$-globin in the blood and bone marrow, with a modest upregulation in the spleen which did not reach statistical significance (Fig. 4). The upregulation of
Ey-globin hemoglobin occurred without major alterations in the expression levels of other embryonic globins, i.e., $\beta$ h1- and $\zeta$-globin. A significant decrease, although very mild, was identified in the bone marrow in the total amount of $\beta$-globin expression compared to the total amount of $\alpha$-globin (Fig. $4 \mathrm{~b})$. This imbalance was not detected in the blood of Asf1b KO mice (Fig. 4a). This suggests that the normal $\alpha / \beta$-globin ratio is restored via a post-transcriptional mechanism, reminiscent of erythropoiesis in individuals with thalassemia trait. Thereof, we conclude that the increased expression of ey-globin is not due to hampered expression of the other globins. Collectively, these data indicate that although not to the same extent as it occurs when knocking down $B C L 11 A$ (direct regulator) or KLF1 (indirect regulator via $B C L 11 A$ and $H B B$ ), lower expression levels of $A S F 1 B$ promote $\gamma$-globin expression, apparently without reducing $H B B$ gene expression. Our data show that $A S F 1 B$ loss of function in mice causes mild dyserythropoiesis with the persistence of ey globin in adult hematopoietic tissues, and thus supporting the notion that the imbalance of $\beta$-like globin expression might be due to dysregulated erythroid differentiation, rather than to a direct role of $A S F 1 B$ in globin switching.

\section{Discussion}

In this study, we report on the role of ASF1B in erythropoiesis and globin gene expression.

ASF1B is known to function as a histone chaperone protein important in chromatin remodeling [27] and nucleosome assembly and disassembly, and when knocked down, it is also known to influence gene expression [43]. It has been recently reported that ASF1B might play a role in epigenetic reprogramming [44, 45], and furthermore, in alternative telomere lengthening [46]. However, the complete spectrum of ASF1B functions has not yet been asserted, and especially interesting is the reported cooperation between ASF1B and general transcription factors such as the TFIID [24, 33]. Microarray analysis on erythroid cells from a family carrying KLF1 p.K288X variant leading to $\mathrm{HPFH}$ showed that family members with high $\mathrm{HbF}$ levels had reduced $A S F 1 B$ gene expression levels compared to family members with normal (low) HbF levels. We studied the possibility of KLF1 directly regulating $A S F 1 B$ expression by performing knockdown experiments on primary HEPs. However, we did not observe significant downregulation of $A S F 1 B$ upon $K L F 1$ knockdown, possibly due to the short-term nature of the knockdown assays. It has been reported that $A S F 1 B$ gene expression is regulated by E2F factors [47, 48]. Since $E 2 F 2$ and $E 2 F 4$ are direct targets of KLF1, and also downregulated in HPFH family members (Fig. 1a), we cannot exclude an indirect contribution of the KLF1 


\section{A Blood}
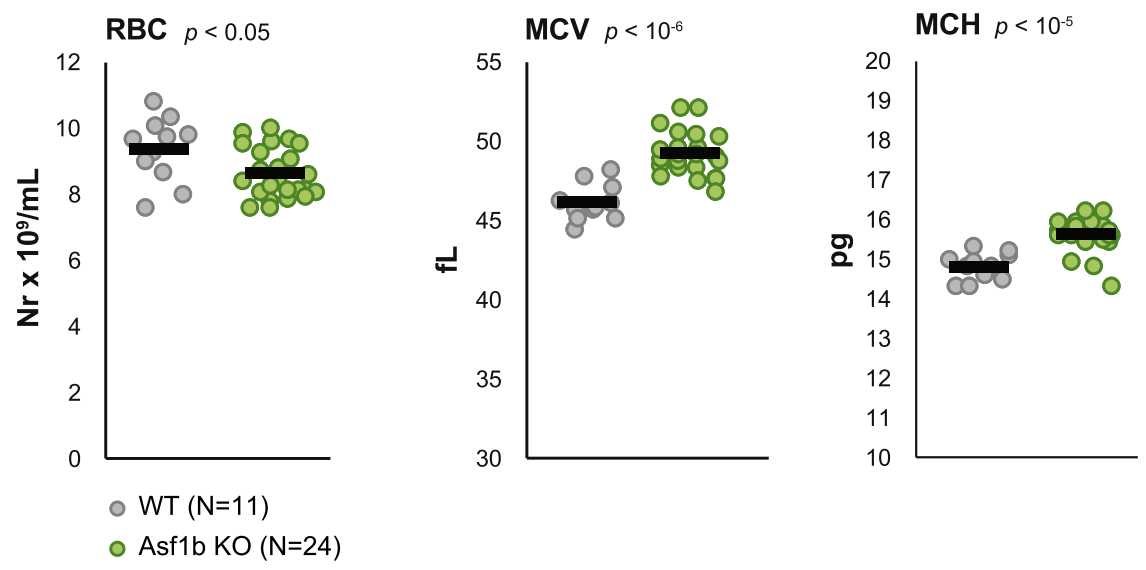

B BM

WT $(\mathrm{N}=5)$

- Asf1b KO $(\mathrm{N}=6)$

○ WT $(\mathrm{N}=5)$

- Asf1b KO $(\mathrm{N}=10)$

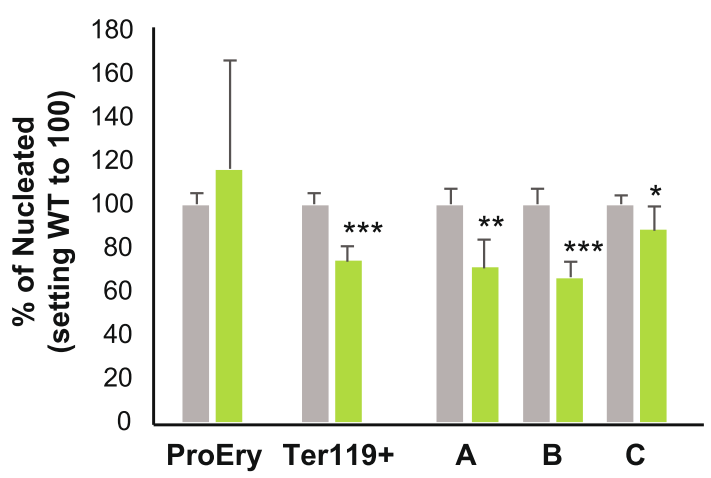

MEP $p<0.005$

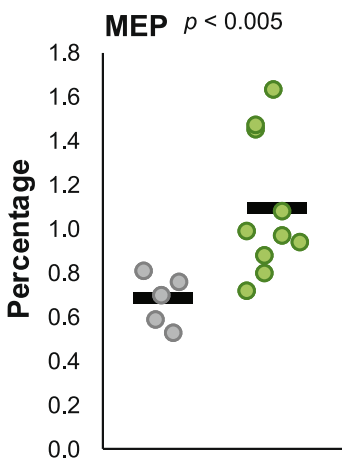

\section{Spleen}

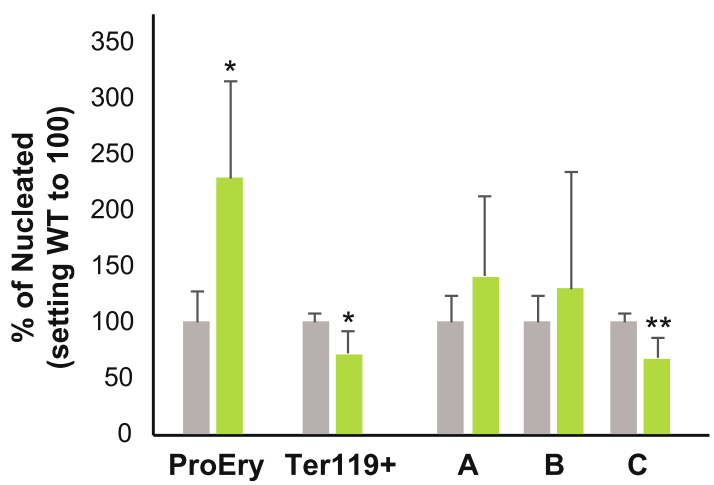

Fig. 3 Asfib KO mice display mild dyserythropoiesis. a Complete blood count of blood samples from Asfib KO mice and WT littermates. The red blood cell (RBC) counts, the mean corpuscular volume (MCV), and mean corpuscular hemoglobin (MCH) are depicted on individual animals. The black bar is the mean. $T$ test $p$ value is indicated. $\mathbf{b}$ Left, bar graph depicting the flow cytometry analysis of the erythroid compartment in the bone marrow of Asf1b KO and WT littermates following the gating strategy of Socolovsky [42]. Right, dot plot depicting the basal percentage of megakaryocyte-erythroid progenitors in the bone marrow of AsfIB KO mice and WT littermates. The black bar is the mean. $T$ test $p$ value is indicated. c Bar graph depicting the flow cytometry analysis of the erythroid compartment in the spleen of Asfib KO and WT littermates following the gating strategy of Socolovsky [42] 
Table 1 Body and spleen weight of Asf1b KO mice and WT littermates. Mice included in this analysis are female littermates from heterozygous crossings. The body weight, spleen weight, and spleen weight/body weight ratio are shown. The mean and standard deviation are indicated. $T$ test $p$ values are given

\begin{tabular}{llll}
\hline Genotype & Body weight $(\mathbf{g})$ & Spleen weight $(\mathbf{m g})$ & Spleen/body weight \\
\hline $\mathrm{WT}(\mathrm{N}=10)$ & $25.93 \pm 2.67$ & $90.20 \pm 13.54$ & $3.50 \pm 0.54$ \\
Asfib KO $(N=8)$ & $28.38 \pm 4.26$ & $124.13 \pm 28.09$ & $4.56 \pm 1.77$ \\
$p$ value & NS & $<0.05$ & NS \\
\hline
\end{tabular}

NS not significant

A

Blood qRT-PCR

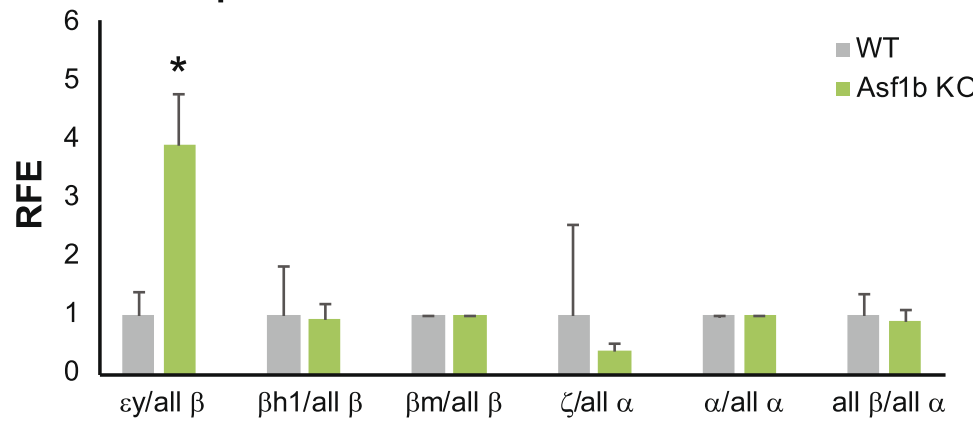

B

\section{BM qRT-PCR}

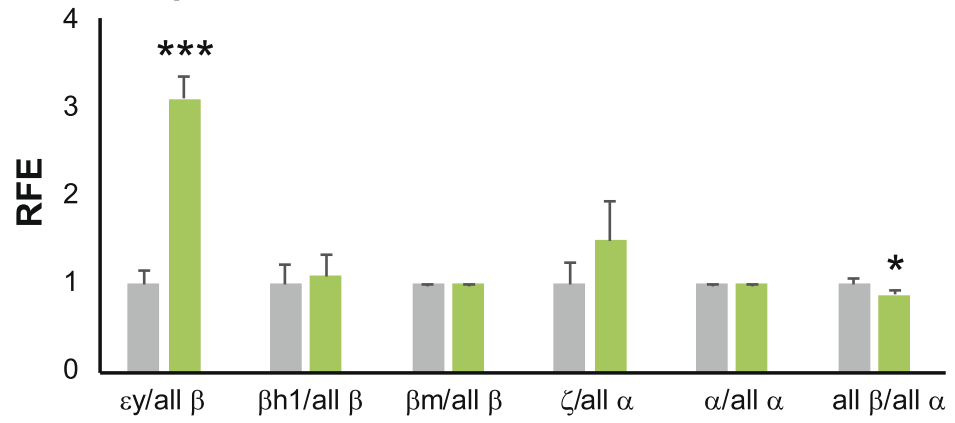

C

Spleen qRT-PCR

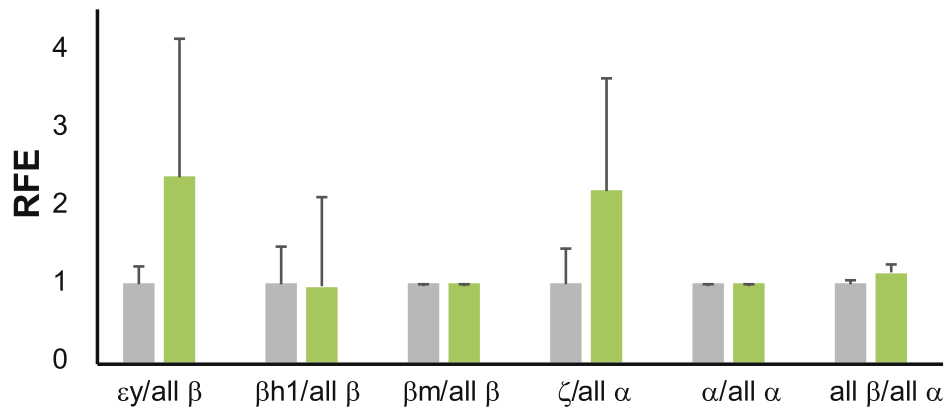

Fig. 4 Persistence of embryonic globin expression in adult Asf1b KO mice. Expression analysis by RT-qPCR of $\beta$-like and a-like globin genes in the blood (a), bone marrow (b), and spleen (c) samples from Asfib KO mice and WT littermates. Ratios of relative fold enrichment (RFE) of a given $\beta$ like or a-like globin versus total $\beta$ - or a-globin, respectively, are depicted. Mean and standard deviation are represented, and $T$ test $p$ values are indicated. ${ }^{*} p<0.05 ;{ }^{* *} p<0.0005$ 
variant to the downregulation of ASF1B expression via E2F2/E2F4.

Importantly, the microarray data shows a significant decrease of $H B B$ gene transcription in those family members with high $\mathrm{HbF}$ levels, similarly to what has been documented for cis-acting genetic variants or SNPs in the $H B B$ gene promoter CACCC box (see also http://globin.bx.psu. edu/hbvar) [20, 21] to which KLF1 binds. In addition, $\gamma$ globin gene expression is upregulated. Thus, it is the balance $\beta$-versus $\gamma$-globin expression that results in the high percentage of $\mathrm{HbF}$, in this case, by directly affecting the expression of $\gamma$ - and $\beta$-globin in an opposite manner.

Since microarrays are not suitable for measuring globin expression due to saturation of the probe sets, we confirmed these dynamics with RT-qPCR analysis in knockdown assays. The results of knockdown experiments of KLF1 and BCL11A in adult erythroid progenitors from healthy donors agreed with such an observation, i.e., increase of $\mathrm{HbF}$ levels compared to the control shRNA, with accompanying decrease in $\beta$-globin expression (Fig. 2). This effect on $\beta$-globin expression downregulation has been seen in single and compound knockout mouse models for Klf1 and Bcl11a [49]. Interestingly, knockdown of ASF1B resulted in an increase of $\mathrm{HbF}$, without significantly altering KLF1, BCL11A, or $\beta$ globin expression (Fig. 2).

It has been recently reported that KLF1 recruits histone chaperones HIRA and ASF1A to maintain an open $\beta$ globin locus and that this recruitment is necessary for proper $\beta$-globin transcription [40]. Although ASF1A and ASF1B are paralogues, it is known that ASF1B does not cooperate with the ASF1A/HIRA complex and that it performs separate actions on nucleosome assembly [28, 37]. Our results are therefore in agreement with this notion, since depletion of ASF1B did not affect $\beta$-globin expression, neither in the Asf $1 b \mathrm{KO}$ mouse model, nor in human erythroid progenitors where ASF1B had been knocked down.

The analogy between KLF1 and ASF1B goes further regarding general erythropoiesis. It has been recognized that a special case of a genetic variant of KLF1 is causative of congenital dyserythropoietic anemia (CDA) variant (type IV) in addition to the accompanying HPFH already reported. Interestingly, the two genes involved in the development of CDA type I are CDAN1 and C15ORF41, both of which have been reported to physically interact with ASF1B [50-55]. This suggests that shared functions by the interacting proteins ASF1B, CDAN1, and C15ORF41 might be crucial during erythropoiesis and for $\beta$-like globin expression regulation.

Indeed, loss of function studies in $A s f 1 b \mathrm{KO}$ mice revealed mild dyserythropoiesis and persistence of $\varepsilon y-$ globin expression in adult hematopoietic tissues, without altering the expression levels of other $\beta$-like globins. While there was a statistically significant reduction of the total $\beta$-like globins compared to $\alpha$-globins, this was only identified in the bone marrow, and it was very mild.

These results, which are in total concordance with our observations in human cellular models of erythropoiesis, indicate that ASF1B fine-tunes erythropoiesis in vivo.

It has been suggested that ASF1B deficiency results in cell cycle defects due to impaired nucleosome assembly $[26,35,36,54,56]$. In this regard, a defective shorter cell cycle during erythropoiesis might result in the production of immature, "skipping division" erythroid cells, which contain higher levels of $\mathrm{HbF}$. In fact, hemolytic treatment in mice or baboons results in an increase of erythroid cells containing fetal/embryonic globin [57, 58]. It has also been described that ASF1B interacts with TFIID [24]. Such interactions involving also transcription regulators, which we have previously shown to be important for mouse erythropoiesis [59], could have a major impact in the coordination between chromatin remodeling, chromatin accessibility, and transcription regulation, and affect consequently gene expression of the $\beta$-like globin genes [24, 33]. Experimental evidence of how ASF1B is involved in these processes (cell cycle/ replication, transcription, epigenetic regulation) and its role in the molecular mechanism behind the transcription/silencing of the $\gamma$-globin genes is missing from our work. Identification of interactors of ASF1B by immunoprecipitation and mass spectrometry as well as cell cycle analysis in erythroid cells should contribute in this direction and should be the subject of future studies.

\section{Conclusions}

In essence, our data indicate that ASF1B cooperates to adult steady-state erythroid differentiation and, most probably associated with this mechanism, it has an accessory function in the silencing of the embryonic globin genes. At present, the exact mechanism by which ASF1B exerts its function related to globin gene expression remains unclear, and further experiments should focus on the molecular characterization of the protein.

\section{Methods \\ Mice}

Asf1b knockout mice were generated as described previously [38]. All animal studies were performed in compliance with the European Community regulation for laboratory animal care and use (Directive 2010/63/UE). The mouse facility of the CEA at Fontenay-aux-Roses received the agreement delivered by the French Ministry of Agriculture (no. D92032-02). Mice were sacrificed by cervical dislocation. All efforts were made to minimize animal stress and suffering. Mice were housed in controlled 12-h light:12-h dark conditions (lights on from 08:00 to 20:00 h) and were supplied with commercial food and tap water ad libitum. The colony of mice was 
maintained by breeding heterozygous mice, so knockout mice could be compared with wild-type littermates and all mating pairs in the same mouse facility. Mouse samples were collected for analysis at 3-8 months of age.

\section{Flow cytometry}

Bone marrow and spleen single-cell suspensions were labeled with respective antibody cocktails. For the analysis of the erythroid compartment, CD71-APCCy7 and Ter119-Pacific Blue antibodies were used (BD), and successive stages of erythroid maturation were calculated as previously described [42]. For MEP analyses, the BM cells were first treated with a $0.75 \% \mathrm{NH}_{4} \mathrm{Cl}$ solution (Sigma-Aldrich, St. Louis, MO, USA) to lyse red blood cells and labeled with a biotinylated lineage cell detection cocktail (Miltenyi Biotec) and revealed by streptavidineFluor450 (eBioscience). The cells were then labeled with PEconjugated anti-CD34, APCCy7-conjugated anti-c-Kit, APC-conjugated anti-Sca-1, and PECy7-conjugated antiCD16/32 (eBioscience) antibodies, and MEPs were identified as Lin-, Sca-1-, c-Kit+, CD16/32-, and CD34- [60]. At least 300,000 cells were acquired.

The cells were analyzed using a FACSCanto II and a SORP LSRII (BD) equipped with blue $(488 \mathrm{~nm})$, violet $(405 \mathrm{~nm})$, and red $(638 \mathrm{~nm})$ lasers. Data were analyzed with the FlowJo software.

\section{Cell cultures}

Human erythroid progenitor cells (HEPs) were cultured as described $[16,61]$ in the presence of recombinant human Epo (Eprex, $1 \mathrm{U} / \mathrm{ml}$ ), recombinant human SCF (100 ng/ $\mathrm{ml})$, and dexamethasone $\left(10^{-6} \mathrm{M}\right.$, Sigma) from processed buffy coats of active blood donors (Sanquin Blood Bank), according to the guidelines of the Declaration of Helsinki and after approval of the local ethical committee. Cells were cultured at $1.5-3 \times 10^{6} / \mathrm{ml}$ through daily dilutions or medium replacement. Cells were counted with an electronic cell counter (CASY-1, Schärfe-System, Germany). To induce terminal differentiation, cells were washed and transferred to medium with recombinant human Epo (Eprex, $10 \mathrm{U} / \mathrm{ml}$ ) and a high concentration of iron-loaded transferrin (Sigma, $0.5 \mathrm{mg} / \mathrm{ml}$ ). Cells were harvested for further analysis (RNA extraction and HPLC) after $24 \mathrm{~h}$ in the differentiation medium.

\section{Transduction of human proerythroblasts with shRNA lentiviral constructs}

Lentivirus was produced by transient transfection of HEK $293 \mathrm{~T}$ cells according to the standard protocols $[16,62]$. Two days after transfection, the supernatant was collected, filtered, and concentrated by centrifugation at $20 \mathrm{k} \mathrm{rpm}$ for $2 \mathrm{~h}$ at $4{ }^{\circ} \mathrm{C}$. HEPs cultured for 1 week from fresh buffy coats from healthy volunteers (Sanquin Blood Supply) were transduced in 24-well plates. We used $0.5 \times 10^{6}$ cells per well and sufficient amounts of virus to transduce $~ 80 \%$ of the cells at day 1 . Puromycin $(1 \mu \mathrm{g} / \mathrm{ml}$ final concentration) was added to the cells at day 2 , and the selection was performed for $24 \mathrm{~h}$. At day 3, cells were induced to differentiate and were harvested at day 4 for RNA extraction and HPLC analysis as described above. The clones from The RNAi Consortium (TRC [63]; Sigma) used were as follows: the non-target SHCOO2 vector (Scrambled "Scr" control; SHC002: 5' -CAACAAGATGAAGAGCACCAA-3'), KLF1 shRNA clone TRCN0000016276, [16] BCL11A shRNA clone TRCN0000033449 (validated by us), and ASF1B shRNA clones TRCN0000074225, TRCN0000074226, and TRCN0000074227, of which only the last two gave significant knockdown. Sequences are listed in Supplementary Table 1.

\section{High-performance liquid chromatography}

Separation and quantification of $\mathrm{Hb}$ fractions were performed by high-performance cation-exchange liquid chromatography (CE-HPLC) on Waters Alliance 2690 equipment (Waters, Milford, MA, USA). The protocol consisted of a 30-min elution over a combined 20-200 $\mathrm{mM} \mathrm{NaCl}$ and $\mathrm{pH} 7.0-6.6$ gradient in $20 \mathrm{mM}$ BisTris/ $\mathrm{HCl}, 2 \mathrm{mM}$ KCN. The column, a PolyCAT A 100/4.6$\mathrm{mm}, 3-\mu \mathrm{m}, 1500-\AA$ column, was purchased from PolyLC (Columbia, MD, USA) [64].

\section{RNA extraction and RT-qPCR analysis}

Total RNA $(1 \mu \mathrm{g})$ from each harvested erythroid cell sample after extraction by TRIzol (Invitrogen) was converted to cDNA with SuperScript II reverse transcriptase according to the manufacturer's instructions (Invitrogen, Paisley, UK). For mouse tissues, the RNeasy Mini Kit (Qiagen) was used to isolate total RNA according to the manufacturer's instructions. Primers used to amplify $B C L 11 A, A S F 1 B, E 2 F 2, E 2 F 4, H B B$, and $H B G 1 / H B G 2$ human genes and mouse globin genes plus controls are listed in Supplementary Table 1.

All amplifications took place with SYBR Green PCR Master Mix (Applied Biosystems). RT-qPCR was performed on the Bio-Rad Optical IQ Thermal Cycler (BioRad) under the following conditions: $50{ }^{\circ} \mathrm{C}$ for $2 \mathrm{~min}$ and $95{ }^{\circ} \mathrm{C}$ for $10 \mathrm{~min}$, followed by 45 cycles of $95{ }^{\circ} \mathrm{C}$ for $30 \mathrm{~s}$ and $62{ }^{\circ} \mathrm{C}$ for $30 \mathrm{~s}$. All reactions were performed in triplicate.

Target gene expression was normalized to GAPDH expression. Gene expression levels were calculated with the 2(-DeltaDeltaC(T)) method [65].

\section{Supplementary information}

Supplementary information accompanies this paper at https://doi.org/10. 1186/s40246-020-00283-3.

Additional file 1. List of shRNA clones and primer sets used. 


\section{Acknowledgements}

Not applicable.

\section{Authors' contributions}

PP designed/performed the experiments, analyzed the data, and wrote the manuscript. AK performed the experiments and analyzed the data. IMDC, $M V, J B, N G, V B, D L$, and ZK performed the experiments. FGG, CMBC, and RvZ designed the experiments and participated in the discussions. MV generated the Asf1b KO mouse model, designed the experiments, analyzed the data, and reviewed the paper. SP, LG, and GPP designed/performed the experiments, analyzed the data, and wrote the paper. All authors read and approved the final manuscript.

\section{Funding}

This work was supported by the European Molecular Biology Organization (EMBO) short-term fellowships (ASTF-2010) and funds from the Comunidad de Madrid "Atracción de Talento" (2016-T1/BMD-1051) to PP; an RYC fellowship (RYC-2013-12587) from the Ministerio de Economía y Competitividad, Spain, and a VENI grant (863.09.012) from The Netherlands Scientific Organization (NWO) to LG; The Netherlands Genomics Initiative (NGI), Erasmus MC (MRace; 296088), the Landsteiner Foundation for Blood Transfusion Research (LSBR; 1040), and ZonMTOP (40-00812-98-12128) to SP; the Centre for Biomedical Genetics (CBG), the European Commission FP6 EuTRACC consortium (037445), the BLUEPRINT Epigenome consortium, and the NIH (R01HL073455) to FG; and the Research Promotion Foundation of Cyprus ( $\Pi \Delta$ E046_02) and the European Commission FP7 GEN2PHEN (200754) projects to GPP.

\section{Availability of data and materials}

Data sharing is not applicable to this article as no datasets were generated or analyzed during the current study.

\section{Ethics approval and consent to participate}

The buffy coats of active blood donors (Sanquin Blood Bank) were processed according to the guidelines of the Declaration of Helsinki and after approval of the local ethical committee.

All animal studies were performed in compliance with the European Community regulation for laboratory animal care and use (Directive 2010/63/ UE). The mouse facility of the CEA at Fontenay-aux-Roses received the agreement delivered by the French Ministry of Agriculture (no. D92032-02).

\section{Consent for publication}

Not applicable.

\section{Competing interests}

The authors declare that they have no competing interests.

\section{Author details}

'Department of Cell Biology, Erasmus MC, Rotterdam, The Netherlands. ${ }^{2}$ Department of Hematology, Hospital Clínico San Carlos, Instituto de Investigación Sanitaria San Carlos (IdISSC), Madrid, Spain. ${ }^{3}$ Department of Blood Cell Research, Sanquin Research and Landsteiner Laboratory, AMC, UvA, Amsterdam, The Netherlands. ${ }^{4}$ UMR Stabilité Génétique Cellules Souches et Radiations, Université de Paris and Université de Paris-Saclay, CEA, 18 route du Panorama, 92260 Fontenay-aux-Roses, France. ${ }^{5}$ U1274, Inserm, 18 route du Panorama, 92260 Fontenay-aux-Roses, France. ${ }^{6}$ Division of Innovative Therapies, UMR1184, Université Paris-Saclay, Inserm, CEA, Center for Immunology of Viral, Auto-immune, Hematological and Bacterial diseases (IMVA-HB/IDMIT), Fontenay-aux-Roses, France. 7 Laboratory of Red Blood Cell Diagnostics, Sanquin Diagnostics, Amsterdam, The Netherlands. ${ }^{8}$ Platelet Research Lab -Instituto de Investigación Sanitaria del Principado de Asturias (ISPA)-, Department of Medicine -University of Oviedo-, Oviedo, Spain. ${ }^{9}$ Laboratory of Pharmacogenomics and Individualized Therapy, Department of Pharmacy, University of Patras School of Health Sciences, Patras, Greece. ${ }^{10}$ Department of Pathology, College of Medicine and Health Sciences and Zayed Center of Health Sciences, United Arab Emirates University, Al-Ain, United Arab Emirates.
Received: 18 July 2020 Accepted: 10 September 2020

Published online: 16 October 2020

\section{References}

1. Stamatoyannopoulos G. Control of globin gene expression during development and erythroid differentiation. Exp Hematol. 2005;33(3):259-71.

2. Noordermeer $D$, de Laat W. Joining the loops: beta-globin gene regulation. IUBMB Life. 2008;60(12):824-33.

3. Palis J. Ontogeny of erythropoiesis. Curr Opin Hematol. 2008;15(3):155-61.

4. Sankaran VG, Xu J, Orkin SH. Advances in the understanding of haemoglobin switching. Br J Haematol. 2010;149(2):181-94.

5. Patrinos GP, Antonarakis SE. Human genetics: problems and approaches; human hemoglobin., 4th edn. Heidelberg: Springer; 2010.

6. Forget BG. Molecular basis of hereditary persistence of fetal hemoglobin. Ann N Y Acad Sci. 1998;850:38-44.

7. Craig JE, Rochette J, Fisher CA, Weatherall DJ, Marc S, Lathrop GM, Demenais F, Thein S. Dissecting the loci controlling fetal haemoglobin production on chromosomes $11 p$ and $6 q$ by the regressive approach. Nat Genet. 1996;12(1):58-64.

8. Liu P, Keller JR, Ortiz M, Tessarollo L, Rachel RA, Nakamura T, Jenkins NA, Copeland NG. Bcl11a is essential for normal lymphoid development. Nat Immunol. 2003;4(6):525-32.

9. Lettre G, Sankaran VG, Bezerra MA, Araujo AS, Uda M, Sanna S, Cao A, Schlessinger D, Costa FF, Hirschhorn JN, et al. DNA polymorphisms at the BCL11A, HBS1L-MYB, and beta-globin loci associate with fetal hemoglobin levels and pain crises in sickle cell disease. Proc Natl Acad Sci U S A. 2008; 105(33):11869-74.

10. Menzel S, Garner C, Gut I, Matsuda F, Yamaguchi M, Heath S, Foglio M, Zelenika D, Boland A, Rooks H, et al. A QTL influencing F cell production maps to a gene encoding a zinc-finger protein on chromosome 2p15. Nat Genet. 2007;39(10):1197-9.

11. Uda M, Galanello R, Sanna S, Lettre G, Sankaran VG, Chen W, Usala G, Busonero F, Maschio A, Albai G, et al. Genome-wide association study shows BCL11A associated with persistent fetal hemoglobin and amelioration of the phenotype of beta-thalassemia. Proc Natl Acad Sci U S A. 2008;105(5):1620-5.

12. Vegiopoulos A, Garcia P, Emambokus N, Frampton J. Coordination of erythropoiesis by the transcription factor c-Myb. Blood. 2006;107(12): 4703-10.

13. Garner C, Mitchell J, Hatzis T, Reittie J, Farrall M, Thein SL. Haplotype mapping of a major quantitative-trait locus for fetal hemoglobin production, on chromosome 6q23. Am J Hum Genet. 1998;62(6):1468-74.

14. Thein SL, Menzel S, Peng X, Best S, Jiang J, Close J, Silver N, Gerovasilli A, Ping $C$, Yamaguchi $M$, et al. Intergenic variants of HBS1L-MYB are responsible for a major quantitative trait locus on chromosome $6 q 23$ influencing fetal hemoglobin levels in adults. Proc Natl Acad Sci U S A. 2007;104(27):11346-51.

15. Stadhouders R, Aktuna S, Thongjuea S, Aghajanirefah A, Pourfarzad F, van ljcken W, Lenhard B, Rooks H, Best S, Menzel S, et al. HBS1L-MYB intergenic variants modulate fetal hemoglobin via long-range MYB enhancers. J Clin Invest. 2014;124(4):1699-710.

16. Borg J, Papadopoulos P, Georgitsi M, Gutierrez L, Grech G, Fanis P, Phylactides M, Verkerk AJ, van der Spek PJ, Scerri CA, et al. Haploinsufficiency for the erythroid transcription factor KLF1 causes hereditary persistence of fetal hemoglobin. Nat Genet. 2010;42(9):801-5.

17. Borg J, Patrinos GP, Felice AE, Philipsen S. Erythroid phenotypes associated with KLF1 mutations. Haematologica. 2011;96(5):635-8.

18. Zhou D, Liu K, Sun CW, Pawlik KM, Townes TM. KLF1 regulates BCL11A expression and gamma- to beta-globin gene switching. Nat Genet. 2010; 42(9):742-4.

19. Sankaran VG, Xu J, Byron R, Greisman HA, Fisher C, Weatherall DJ, Sabath DE, Groudine M, Orkin SH, Premawardhena A, et al. A functional element necessary for fetal hemoglobin silencing. N Engl J Med. 2011;365(9):807-14.

20. Giardine B, Borg J, Viennas E, Pavlidis C, Moradkhani K, Joly P, Bartsakoulia M, Riemer C, Miller W, Tzimas G, et al. Updates of the HbVar database of human hemoglobin variants and thalassemia mutations. Nucleic Acids Res. 2014;42(Database issue):D1063-9.

21. Treisman R, Orkin SH, Maniatis T. Specific transcription and RNA splicing defects in five cloned beta-thalassaemia genes. Nature. 1983;302(5909):591-6.

22. Liu D, Zhang X, Yu L, Cai R, Ma X, Zheng C, Zhou Y, Liu Q, Wei X, Lin L, et al. KLF1 mutations are relatively more common in a thalassemia endemic 
region and ameliorate the severity of beta-thalassemia. Blood. 2014;124(5): 803-11.

23. Peng H, Nogueira ML, Vogel $J$, Kristie TM. Transcriptional coactivator HCF-1 couples the histone chaperone Asf1b to HSV-1 DNA replication components. Proc Natl Acad Sci U S A. 2010;107(6):2461-6.

24. Chimura T, Kuzuhara T, Horikoshi M. Identification and characterization of CIA/ASF1 as an interactor of bromodomains associated with TFIID. Proc Natl Acad Sci U S A. 2002;99(14):9334-9.

25. Dennehey BK, Noone S, Liu WH, Smith L, Churchill ME, Tyler JK. The C terminus of the histone chaperone Asf1 cross-links to histone $\mathrm{H} 3$ in yeast and promotes interaction with histones H3 and H4. Mol Cell Biol. 2013;33(3): 605-21.

26. Munakata T, Adachi N, Yokoyama N, Kuzuhara T, Horikoshi M. A human homologue of yeast anti-silencing factor has histone chaperone activity. Genes Cells. 2000;5(3):221-33.

27. Galvani A, Courbeyrette R, Agez M, Ochsenbein F, Mann C, Thuret JY. In vivo study of the nucleosome assembly functions of ASF1 histone chaperones in human cells. Mol Cell Biol. 2008;28(11):3672-85.

28. Abascal F, Corpet A, Gurard-Levin ZA, Juan D, Ochsenbein F, Rico D, Valencia A, Almouzni G. Subfunctionalization via adaptive evolution influenced by genomic context: the case of histone chaperones ASF1a and ASF1b. Mol Biol Evol. 2013;30(8):1853-66.

29. Paul PK, Rabaglia ME, Wang CY, Stapleton DS, Leng N, Kendziorski C, Lewis PW, Keller MP, Attie AD. Histone chaperone ASF1B promotes human betacell proliferation via recruitment of histone H3.3. Cell Cycle. 2016;15(23): 3191-202.

30. Li Z, Gourguechon S, Wang CC. Tousled-like kinase in a microbial eukaryote regulates spindle assembly and S-phase progression by interacting with Aurora kinase and chromatin assembly factors. J Cell Sci. 2007;120(Pt 21): 3883-94.

31. Pilyugin M, Demmers J, Verrijzer CP, Karch F, Moshkin YM. Phosphorylationmediated control of histone chaperone ASF1 levels by Tousled-like kinases. PLoS One. 2009;4(12):e8328.

32. Sillje HH, Nigg EA. Identification of human Asf1 chromatin assembly factors as substrates of Tousled-like kinases. Curr Biol. 2001;11(13):1068-73.

33. Umehara T, Horikoshi M. Transcription initiation factor IID-interactive histone chaperone CIA-II implicated in mammalian spermatogenesis. J Biol Chem. 2003;278(37):35660-7.

34. Yang JH, Choi JH, Jang H, Park JY, Han JW, Youn HD, Cho EJ. Histone chaperones cooperate to mediate Mef2-targeted transcriptional regulation during skeletal myogenesis. Biochem Biophys Res Commun. 2011;407(3): 541-7.

35. Mello JA, Sillje HH, Roche DM, Kirschner DB, Nigg EA, Almouzni G. Human Asf1 and CAF-1 interact and synergize in a repair-coupled nucleosome assembly pathway. EMBO Rep. 2002;3(4):329-34.

36. Tyler JK, Adams CR, Chen SR, Kobayashi R, Kamakaka RT, Kadonaga JT. The RCAF complex mediates chromatin assembly during DNA replication and repair. Nature. 1999:402(6761):555-60.

37. Tang Y, Poustovoitov MV, Zhao K, Garfinkel M, Canutescu A, Dunbrack R, Adams PD, Marmorstein R. Structure of a human ASF1a-HIRA complex and insights into specificity of histone chaperone complex assembly. Nat Struct Mol Biol. 2006;13(10):921-9.

38. Messiaen S, Guiard J, Aigueperse C, Fliniaux I, Tourpin S, Barroca V, Allemand I, Fouchet P, Livera G, Vernet M. Loss of the histone chaperone ASF1B reduces female reproductive capacity in mice. Reproduction. 2016; 151(5):477-89.

39. Drissen $R$, von Lindern M, Kolbus A, Driegen S, Steinlein P, Beug H, Grosveld F, Philipsen S. The erythroid phenotype of EKLF-null mice: defects in hemoglobin metabolism and membrane stability. Mol Cell Biol. 2005;25(12): 5205-14.

40. Soni S, Pchelintsev N, Adams PD, Bieker JJ. Transcription factor EKLF (KLF1) recruitment of the histone chaperone HIRA is essential for beta-globin gene expression. Proc Natl Acad Sci U S A. 2014;111(37):13337-42.

41. Sankaran VG, Menne TF, Xu J, Akie TE, Lettre G, Van Handel B, Mikkola HK, Hirschhorn JN, Cantor AB, Orkin SH. Human fetal hemoglobin expression is regulated by the developmental stage-specific repressor BCL11A. Science. 2008;322(5909):1839-42.

42. Socolovsky M. Molecular insights into stress erythropoiesis. Curr Opin Hematol. 2007;14(3):215-24.

43. Corpet A, De Koning L, Toedling J, Savignoni A, Berger F, Lemaitre C, O'Sullivan RJ, Karlseder J, Barillot E, Asselain B, et al. Asf1b, the necessary
Asf1 isoform for proliferation, is predictive of outcome in breast cancer. EMBO J. 2011;30(3):480-93.

44. Awe JP, Byrne JA. Identifying candidate oocyte reprogramming factors using cross-species global transcriptional analysis. Cell Rep. 2013;15(2):126-33.

45. Evans E, Hogarth C, Mitchell D, Griswold M. Riding the spermatogenic wave: profiling gene expression within neonatal germ and sertoli cells during a synchronized initial wave of spermatogenesis in mice. Biol Reprod. 2014; 90(5):108.

46. O'Sullivan RJ, Arnoult N, Lackner DH, Oganesian L, Haggblom C, Corpet A, Almouzni G, Karlseder J. Rapid induction of alternative lengthening of telomeres by depletion of the histone chaperone ASF1. Nat Struct Mol Biol. 2014;21(2):167-74.

47. Hayashi R, Goto Y, Tanaka R, Oonogi K, Hisasue M, Yoshida K. Transcriptional regulation of human chromatin assembly factor ASF1. DNA Cell Biol. 2007; 26(2):91-9.

48. Lario LD, Ramirez-Parra E, Gutierrez C, Spampinato CP, Casati P. ANTI-SILENC ING FUNCTION1 proteins are involved in ultraviolet-induced DNA damage repair and are cell cycle regulated by E2F transcription factors in Arabidopsis. Plant Physiol. 2013;162(2):1164-77.

49. Esteghamat F, Gillemans N, Bilic I, van den Akker E, Cantu I, van Gent T, Klingmuller U, van Lom K, von Lindern M, Grosveld F, et al. Erythropoiesis and globin switching in compound Klf1::Bcl11a mutant mice. Blood. 2013; 121(13):2553-62.

50. Babbs C, Roberts NA, Sanchez-Pulido L, McGowan SJ, Ahmed MR, Brown JM, Sabry MA, Consortium WGS, Bentley DR, McVean GA, et al. Homozygous mutations in a predicted endonuclease are a novel cause of congenital dyserythropoietic anemia type I. Haematologica. 2013;98(9):1383-7.

51. Iolascon A, Heimpel H, Wahlin A, Tamary H. Congenital dyserythropoietic anemias: molecular insights and diagnostic approach. Blood. 2013;122(13): 2162-6.

52. Ahmed MR, Chehal A, Zahed L, Taher A, Haidar J, Shamseddine A, O'Hea AM, Bienz N, Dgany O, Avidan N, et al. Linkage and mutational analysis of the CDAN1 gene reveals genetic heterogeneity in congenital dyserythropoietic anemia type I. Blood. 2006;107(12):4968-9.

53. Noy-Lotan S, Dgany O, Lahmi R, Marcoux N, Krasnov T, Yissachar N, Ginsberg D, Motro B, Resnitzky P, Yaniv I, et al. Codanin-1, the protein encoded by the gene mutated in congenital dyserythropoietic anemia type I (CDAN1), is cell cycle-regulated. Haematologica. 2009;94(5):629-37.

54. Ask K, Jasencakova Z, Menard P, Feng Y, Almouzni G, Groth A. Codanin-1, mutated in the anaemic disease CDAl, regulates Asf1 function in S-phase histone supply. EMBO J. 2012;31(8):2013-23.

55. Russo R, Marra R, Andolfo I, De Rosa G, Rosato BE, Manna F, Gambale A, Raia M, Unal S, Barella S, et al. Characterization of two cases of congenital dyserythropoietic anemia type I shed light on the uncharacterized C15orf41 protein. Front Physiol. 2019;10:621.

56. Loyola A, Almouzni G. Histone chaperones, a supporting role in the limelight. Biochim Biophys Acta. 2004;1677(1-3):3-11.

57. DeSimone J, Biel M, Heller P. Maintenance of fetal hemoglobin ( $\mathrm{HbF}$ ) elevations in the baboon by prolonged erythropoietic stress. Blood. 1982;60(2):519-23.

58. Papadopoulos P, Gutierrez L, van der Linden R, Kong ASJ, Maas A, Drabek D, Patrinos GP, Philipsen S, Grosveld F. A dual reporter mouse model of the human beta-globin locus: applications and limitations. PLoS One. 2012;7(12): e51272.

59. Papadopoulos P, Gutierrez L, Demmers J, Scheer E, Pourfarzad F, Papageorgiou DN, Karkoulia E, Strouboulis J, van de Werken HJ, van der Linden $\mathrm{R}$, et al. TAF10 interacts with the GATA1 transcription factor and controls mouse erythropoiesis. Mol Cell Biol. 2015;35(12):2103-18.

60. Kusy S, Gault N, Ferri F, Lewandowski D, Barroca V, Jaracz-Ros A, Losson R, Romeo PH. Adult hematopoiesis is regulated by TIF1gamma, a repressor of TAL1 and PU.1 transcriptional activity. Cell Stem Cell. 2011;8(4):412-25.

61. von Lindern M, Zauner W, Mellitzer G, Steinlein P, Fritsch G, Huber K, Lowenberg B, Beug $H$. The glucocorticoid receptor cooperates with the erythropoietin receptor and c-Kit to enhance and sustain proliferation of erythroid progenitors in vitro. Blood. 1999;94(2):550-9.

62. Zufferey R, Nagy D, Mandel RJ, Naldini L, Trono D. Multiply attenuated lentiviral vector achieves efficient gene delivery in vivo. Nat Biotechnol. 1997;15(9):871-5.

63. Moffat J, Grueneberg DA, Yang X, Kim SY, Kloepfer AM, Hinkle G, Piqani B, Eisenhaure TM, Luo B, Grenier JK, et al. A lentiviral RNAi library for human and mouse genes applied to an arrayed viral high-content screen. Cell. 2006;124(6):1283-98. 
64. van Zwieten R, Veldthuis M, Delzenne B, Berghuis J, Groen J, Ait Ichou F, Clifford E, Harteveld CL, Stroobants AK. Hemoglobin analyses in the

Netherlands reveal more than 80 different variants including six novel ones. Hemoglobin. 2014;38(1):1-7.

65. Schmittgen TD, Livak KJ. Analyzing real-time PCR data by the comparative C(T) method. Nat Protoc. 2008;3(6):1101-8.

\section{Publisher's Note}

Springer Nature remains neutral with regard to jurisdictional claims in published maps and institutional affiliations.

Ready to submit your research? Choose BMC and benefit from:

- fast, convenient online submission

- thorough peer review by experienced researchers in your field

- rapid publication on acceptance

- support for research data, including large and complex data types

- gold Open Access which fosters wider collaboration and increased citations

- maximum visibility for your research: over $100 \mathrm{M}$ website views per year

At $B M C$, research is always in progress.

Learn more biomedcentral.com/submissions 